\title{
APLIKASI AR-CA (AUGMENTED REALITY RELIEF CANDI JAGO) SEBAGAI UPAYA PENDOKUMENTASIAN DIGITAL RELIEF CANDI JAGO DAN PENGENALAN WISATA SEJARAH DI MALANG
}

\author{
Noveria Anggraeni Fiaji*1, Komang Candra Brata ${ }^{2}$, Prima Zulvarina ${ }^{3}$ \\ ${ }^{1}$ Fakultas Ilmu Sosial dan Ilmu Politik Universitas Brawijaya \\ ${ }^{2,3}$ Fakultas Ilmu Komputer Universitas Brawijaya \\ Email: ${ }^{1}$ novafiaji@ub.ac.id , ${ }^{2}$ k.candra.brata@ub.ac.id, ${ }^{3}$ primazulvarina@ub.ac.id \\ *Penulis Korespondensi
}

(Naskah masuk: 02 Desember 2020, diterima untuk diterbitkan: 21 Juli 2021)

\begin{abstract}
Abstrak
Penelitian ini bertujuan untuk mendigitalisasikan cerita fabel yang terdapat dalam relief Candi Jago sebagai upaya memperkenalkan dan mempertahankan kearifan lokal Malang. Relief Candi Jago dipilih karena belum ada pendokumentasian yang optimal terhadap cerita relief tersebut sehingga ketertarikan pada para calon wisatawan untuk mengunjungi lokasi tersebut sangat kurang. Untuk menjawab permasalahan tersebut, maka dilakukan penelitian pengembangan melalui aplikasi AR-CA. Aplikasi AR-CA merupakan aplikasi pemanfaatan augmented reality melalui teknologi yang dapat menjadikan sarana pembelajaran informasi menjadi lebih interaktif dan menarik. Dalam penelitian ini, pendokumentasian cerita relief Candi Jago melalui digital menggunakan pengembangan model desain Recursive, Reflective, Design, and Development (R2D2). Model R2D2 akan memfokuskan pada tiga fokus pengembangan, (1) fokus penetapan, (2) fokus pengembangan desain produk, serta tahap uji kelayakan, dan (3) fokus diseminasi sesuai dengan konteks lingkungan pengembangan dan kebutuhan. Fokus penelitian ini ada dua 1) Tahapan konsep penyusunan Pendokumentasian relief Candi Jago dengan menggunakan aplikasi Augmented Reality (AR) dan 2) Memaparkan Fitur-fitur yang terdapat dalam aplikasi AR-CA. Hasil dari Penelitian ini mengenai tahapan konsep penyusunan, Pertama, pemilihan cerita yang terdapat dalam relief Candi Jago. Kedua, mengubah ketiga cerita yang telah dipilih, berupa teks cerita menjadi teks drama. Ketiga, menentukan marker agar dapat menampilkan objek virtual. Keempat, menentukan tokoh-tokoh sentral dalam setiap cerita yang telah dipilih sebagai icon cerita. Kelima, membuat video animasi berdasarkan teks drama yang telah dibuat pada tahap kedua. Keenam, merancang aplikasi AR sebagai jembatan marker yang akan menampilkan objek virtual. Fitur-fitur yang terdapat dalam aplikasi AR-CA yaitu fitur kamera AR, fitur cerita yang berisi tiga video animasi yang menggambarkan cerita relief Candi Jago yaitu Kera yang malang, Serigala si Penghasut, Kura-kura yang bandel. Selanjutnya fitur bantuan, fitur tentang, dan control panel keluar.
\end{abstract}

Kata kunci: Relief, Candi Jago, Digital, Wisata Sejarah, Augmented Reality (AR)

\section{DEVELOPING THE AR-CA (AUGMENTED REALITY OF JAGO TEMPLE'S RELIEF) APPLICATION AS AN EFFORT TO DOCUMENT DIGITAL JAGO TEMPLE'S RELIEF AND PROMOTE MALANG'S HISTORICAL TOURISM}

\begin{abstract}
This study aimed to produce a digital instrument for exhibiting temple-relief of Jago Temple as a part of Malang's tourism promotion and sustainability program. Moreover, this study focused on Jago Temple's relief due to its limited documentation by far which impacted to the small number of tourists visiting the historical site. Therefore, the AR-CA application was developed to provide solution for the particular issue. AR-CA adopted augmented reality technology to create a learning instrument which is able to deliver more interactive and attractive information. For this study, Recursive, Reflective, Design and Development (R2D2) instructional design model was employed to document the story depicted by the Jago Temple's relief into a digital form. The R2D2 model would focus on three development methods, (1) defining, (2) designing and developing, and (3) disseminating based on the relevant circumstances and requirements. Furthermore, this study offered two primary results 1) planning stage which is to document Jago Temple's relief using the augmented reality (AR) application and 2) delivering features on the AR-CA. More specifically, on the planning stage, this study broke down, 1) selecting which stories were going to be exhibited 2) translating the prose into drama text, 3)
\end{abstract}


determining marker to show virtual objects, 4) selecting primary figures within the stories, 5) creating animation video depicting the generated drama text, 6) developing AR application which would present the virtual objects. Meanwhile, this AR-CA application provided a number of features including AR camera, Video Playlist containing three animation videos about a poor ape, deceitful wolf and naughty turtle, Help, About App, and Log Out.

Keywords: temple-relief, Jago Temple, digital, historical tourism, augmented reality (AR)

\section{PENDAHULUAN}

Malang Raya yang terdiri dari Kota Malang, Kabupaten Malang, dan Kota Batu memiliki banyak sekali bangunan bersejarah di era sebelum dan sesudah kemerdekaan yang masih terjaga hingga saat ini. Salah satu bentuk peninggalan sejarah tersebut berupa bangunan candi, yakni Candi Singosari, Candi Badut, dan Candi Jago yang terdapat di Kabupaten Malang. Akan tetapi, dengan berkurangnya ketertarikan jumlah wisatawan untuk mengunjungi tempat wisata sejarah tentunya juga berakibat pada ketidaktahuan masyarakat lokal mengenai kearifan lokal di daerahnya. Candi Jago merupakan salah satu candi di Kabupaten Malang yang masih terjaga akan kekhasan bangunannya dan apabila dipelajari lebih jauh, bagian relief Candi Jago juga memiliki cerita fabel yang sarat akan nilai moral, terutama bagi anak usia dini. Kurangnya informasi dan minat masyarakat untuk mempelajari dan mengunjungi destinasi wisata sejarah, memberikan sebuah tantangan baru bagi para peneliti untuk dapat memberikan sumbangsih ilmu pengetahuan atas persoalan yang dihadapi.

Penelitian ini merupakan Penelitian Pengembangan. Penulis memiliki gagasan atau ide untuk ditawarkan yakni pendokumentasian digital relief Candi Jago berupa aplikasi mobile dengan menggunakan sistem Android dan pengembangan Augmented Reality (AR) yang dapat dijadikan sebagai salah satu alternatif atas persoalan tersebut. Proses digitalisasi dipilih karena perkembangan teknologi tumbuh dengan sedemikian pesatnya dan lebih dekat dengan masyarakat. Teknologi di dunia pariwisata dan pendidikan merupakan suatu hal yang sangat penting untuk membantu setiap individu menjadi lebih aktif khususnya bagi para wisatawan dari kalangan pelajar. Menurut Courduff (2011), teknologi mampu membuka kunci pembelajaran kepada semua siswa. Hal tersebut senada dengan pendapat Baytak, Tarman, dan Ayas (2011) yang menyatakan sebagian besar siswa meyakini bahwa pembelajaran menggunakan teknologi membuat pelajaran menjadi menyenangkan, sehingga hal itu dapat menjadi pembelajaran yang lebih menarik. Dari kedua pendapat ahli tersebut diperkuat dengan penelitian yang dilakukan Fiaji (2019) bahwasannya perkembangan teknologi dapat mempengaruhi pergeseran nilai seseorang, sehingga peran teknologi menaruh peran penting dalam proses pembentukan nilai kehidupan manusia. Sehingga peran dari penggunaan teknologi pada aplikasi ini di rasa tepat karena pada relief Candi Jago terdapat nilai moral yang dapat digunakan sebagai media pembelajaran untuk pembentukan nilai moral.

Pendokumentasian digital dengan menggunakan aplikasi ini dirasa cukup menarik karena mengajak wisatawan untuk ikut dalam pusaran arus cerita yang terdapat dalam relief melalui aplikasi Augmented Reality (AR). Sehingga, peneliti akan memfokuskan pada dua tujuan penelitian yakni 1) tahapan konsep penyusunan Pendokumentasian relief Candi Jago dengan menggunakan aplikasi Augmented Reality (AR) dan 2) memaparkan Fitur-fitur yang terdapat dalam aplikasi AR-CA.

\section{METODE PENELITIAN}

Pengembangan aplikasi AR dalam penelitian ini menggunakan langkah pengembangan model desain Recursive, Reflective, Design, and Development atau dapat disingkat R2D2. Model R2D2 memiliki tiga fokus pengembangan, yaitu (1) fokus penetapan (define focus), (2) fokus penentuan desain dan pengembangan (design and development focus), dan (3) fokus penyebarluasan (dissemination focus) sesuai dengan konteks lingkungan pengembangan dan kebutuhan. Data pada penelitian ini adalah data kualitatif. Instrumen pengumpulan data dalam penelitian ini adalah berupa lembar wawancara dan lembar angket. Jenis angket yang digunakan dalam penelitian ini adalah angket terbuka. Analisis data yang sudah terkumpul dilakukan dengan menggunakan analisis persentase dan deskriptif kualitatif. Data penelitian ini adalah data validasi hasil pengembangan aplikasi AR yang diperoleh ketika uji produk. Hasil penilaian dalam uji produk melalui angket penilaian menunjukkan kualitas draf media pembelajaran yang dikembangkan. Hasil analisis data ini selanjutnya dipergunakan untuk merevisi produk buku saku digital, mengkaji produk, dan memberikan saran pemanfaatan, diseminasi, dan pengembangan produk lebih lanjut.

\section{LANDASAN PUSTAKA}

Penelitian ini bukan merupakan satu-satunya penelitian yang memanfaatkan media AR sebagai salah satu komponen penelitian. Penelitian serupa pernah dilakukan oleh Juniawan, dkk (2019) dengan judul Pengenalan alat musik Tradisional Bangka dengan Marker-Based Augmented Reality. Dalam 
penelitian tersebut menyatakan bahwasannya teknologi membuat kesadaran akan pentingnya alat musik tradisional berkurang, hal tersebut mungkin ada benarnya dari sisi penelitian sebelumnya, akan tetapi jika dapat berpikir lebih jauh justru teknologi dapat dimanfaatkan sebagai media pengenalan alat musik tradisional di kalangan masyarakat. Kesamaan penelitian tersebut dengan penelitian yang akan dilakukan yakni sama-sama menggunakan AR dengan metode berbasis marker. Metode tersebut dipilih oleh peneliti sebelumnya karena pengguna yang mayoritas masih anak-anak dengan kelebihan memiliki tingkat akurasi yang sangat tinggi. Metode yang membedakan penelitian kali ini dengan sebelumnya, yakni kelebihan yang terdapat pada aplikasi AR dapat dinikmati oleh semua kalangan masyarakat terutama anak-anak, selain itu kelebihan dari aplikasi AR ini menampilkan video animasi berupa cerita fabel dan penyusunan puzzle sebagai daya tarik anak-anak dalam menggunakan aplikasi.

\subsection{Digitalisasi}

Digitalisasi merupakan bentuk pengalihan media dari yang semula masih berbentuk cetak, audio, maupun video disederhanakan menjadi bentuk digital atau dokumen elektronik. (Asaniyah, 2017).

\subsection{Aplikasi Mobile (Mobile Aplication)}

Pendokumentasian Relief Candi Jago pada penelitian ini menggunakan aplikasi mobile. Menurut Brata (2019) Aplikasi mobile yaitu aplikasi yang dijalankan pada perangkat mobile yang pada saat ini banyak berjalan pada perangkat smartphone. Selanjutnya, aplikasi ini dimungkinkan untuk digunakan karena aplikasi mobile memungkinkan mobilitas menggunakan perlengkapan seperti wearable, handphone atau perangkat seluler.

\subsection{Android}

Sistem operasi yang digunakan dalam penelitian ini menggunakan Android. Android menurut matsun merupakan salah satu sistem operasi yang paling banyak digunakan pada smartphone masa kini (Matsun, et al., 2018).

\subsection{Augmented Reality (AR)}

Ariftama, dkk (2018) menyatakan bahwa AR merupakan sebuah teknologi di bidang multimedia yang memungkinkan pengguna untuk memvisualisasikan dunia maya sebagai bagian dari dunia nyata yang seakan terhubung dan berinteraksi dengan dunia nyata.

\subsection{Marker}

Pada penelitian kali ini menggunakan Single Marker. Single Marker atau yang dikenal sebagai satu penanda dalam Augmented Reality, satu penanda dalam mendeteksi gambar yang dijadikan sebagai media marker dan hanya satu objek saja yang keluar. (Apriyani, et al., 2015)

\section{HASIL DAN PEMBAHASAN}

Berdasarkan penelitian yang telah dilakukan, berikut data-data penelitian yang akan disajikan meliputi, (1) tahapan konsep penyusunan Pendokumentasian relief Candi Jago dengan menggunakan aplikasi Augmented Reality (AR); dan (2) Pemaparan fitur-fitur yang terdapat dalam aplikasi AR-CA.

\subsection{Tahapan Konsep Penyususnan Pendokumentasian Relief Candi Jago dengan menggunakan Aplikasi Augmented Reality (AR)}

Konsep cerita digital relief Candi Jago dapat disusun berdasarkan data awal penelitian hasil wawancara yang telah dilakukan oleh satu orang dari dinas pariwisata, dan lima responden pengunjung Candi Jago menunjukkan bahwasannya sebanyak enam responden pengunjung Candi Jago merasakan perlunya peran teknologi utuk menjembatani pembelajaran sejarah di era modernitas saat ini yakni berupa video animasi. Pendokumentasian cerita Relief Candi Jago disusun dengan menggunakan aplikasi AR dinilai sangat menarik karena menyajikan cerita relief secara langsung, nyata, dan sebagai wujud pengenalan cerita fabel kepada masyarakat luas dan khususnya pada generasi milenial. Craig dalam Prasetiyo (2017) juga menjelaskan bahwa sebagai suatu media, AR menggunakan cara yang berbeda-beda. AR berusaha memberikan pengalaman yang berbeda melalui indera penglihatan (visual) manusia.

Terdapat enam tahapan konsep penyusunan dalam mendokumentasikan AR. Berikut uraian dari keenam tahapan konsep penyusunan pendokumentasian relief Candi Jago melalui AR.

1. Pemilihan cerita yang terdapat dalam relief, pada tahap ini menentukan cerita relief Candi Jago yang akan didokumentasikan menggunakan aplikasi AR. Terdapat tujuh cerita relief Candi Jago pada teras pertama, dipilih tiga cerita berdasarkan urutan panel cerita yang terdapat pada relief dan ketiga cerita tersebut nantinya akan digunakan sebagai cerita yang didokumentasikan melalui aplikasi AR. Ketiga cerita tersebut adalah cerita Papaka, Harimau dan Kera; cerita Harimau dan Banteng; dan cerita KuraKura dan Angsa.

2. Mengubah ketiga cerita yang dipilih menjadi teks drama. Ketiga cerita yang dipilih berbentuk teks cerita merupakan hasil penelitian yang dilakukan Fauzi (2018) hasil penelitian tersebut menghasilkan dokumentasi tertulis cerita relief Candi Jago yang terdapat pada teras pertama. Ketiga teks cerita yang dipilih dari ketujuh cerita dalam satu teras diubah menjadi teks drama dengan tujuan untuk 
memudahkan pembuatan cerita dan dialog dalam video animasi.

3. Pada tahap penentuan marker agar dapat menampilkan objek virtual, dipilih dua marker yang akan digunakan. Marker pertama merupakan lukisan Candi Jago tampak depan yang nantinya akan dibuat puzzle untuk menarik perhatian pengguna. Marker lukisan Candi Jago dipilih untuk pengguna yang tidak dapat berkunjung langsung menikmati relief Candi Jago. Marker kedua adalah pahatan reliefrelief yang terdapat pada teras pertama dengan penyesuaian urutan panel cerita.
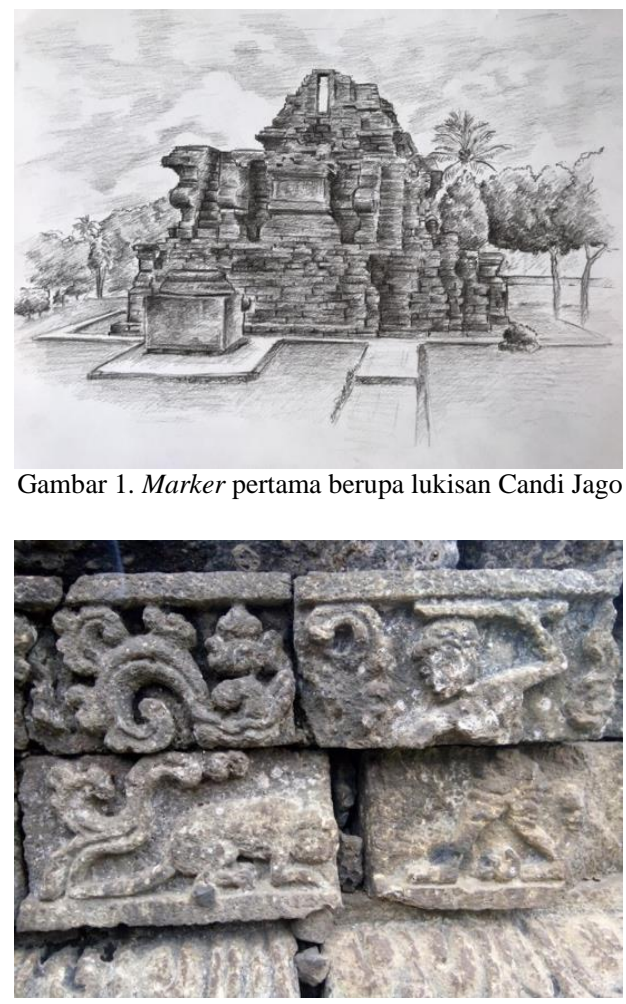

Gambar 2. Marker kedua relief cerita Papaka

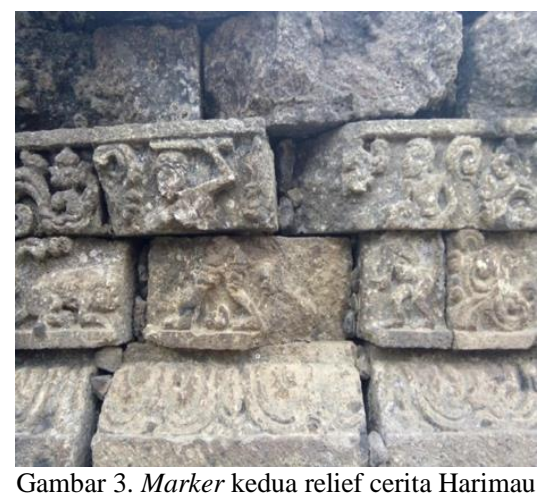

4. Penentuan tokoh-tokoh sentral dalam setiap cerita yang telah dipilih sebagai icon cerita dimaksudkan untuk mengenalkan tokoh hewan yang terdapat dalam gambar pahatan relief. Hal tersebut bertijuan untuk lebih memahamkan pahatan gambar yang termuat dalam relief tersebut. Sebagai contoh pada cerita Papaka, Harimau, dan Kera, tokoh sentral yang terpahat dalam relief adalah tokoh Papaka yang dalam hal ini adalah seorang pemburu.
5. Pada tahap ini adalah pembuatan video animasi berdasarkan teks drama yang telah dibuat pada tahap kedua. Video animasi dibuat sebagai wujud dokumentasi digital yang akan digunakan sebagai objek virtual, tiga video animasi berdasarkan pada pemilihan cerita pada tahap pertama.

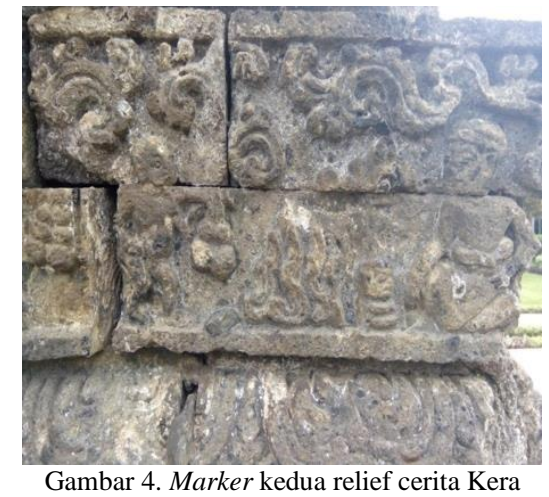

6. Cara kerja aplikasi AR dapat diuraikan pada tahap keenam. Sebelum marker dapat memunculkan objek virtual, terlebih dahulu aplikasi AR dirancang dan diinstal pada android sehingga dapat dioperasikan. Marker lukisan Candi Jago dibuat dalam satu lembaran. Gambar dalam marker pertama, pengguna tidak perlu berkunjung ke Candi Jago, cukup dengan men-scan marker dengan gawai yang telah terinstal aplikasi untuk mengetahui cerita relief yang terdapat di Candi Jago. Untuk marker kedua, bagi pengguna yang berkunjung ke Candi Jago, pengunjung dapat langsung menggunakan aplikasi AR dengan cara men-scan gambar patahan relief sesuai panel cerita sehingga muncul video animasi yang menceritakan rangkaian pahatan pada relief.

\subsection{Fitur-Fitur pada Aplikasi AR-CA}

AR-CA merupakan nama aplikasi yang dipilih berdasarkan pada nilai filosofis dan kebermaknaan dari aplikasi tersebut. AR-CA memiliki kebermaknaan makna, yakni AR merupakan akronim dari Aplikasi Relief dan bisa juga Augmented Reality (AR) berdasarkan dari cikal bakal pembuatan aplikasi ini. Berikut konsep aplikasi AR-CA sebagai aplikasi media pengenalan wisata sejarah di Kabupaten Malang.

\section{Logo Aplikasi pada Android}

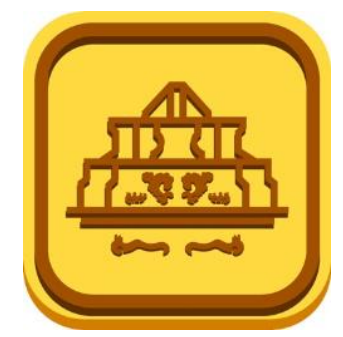

Gambar 5. Logo Aplikasi AR-CA pada Android 
Tampak dari menu Home ponsel pintar logo aplikasi AR-CA. Logo tersebut berupa siluet Candi Jago. Dengan dominasi warna background kuning dan siluet orange serta coklat.

\section{Halaman Awal Aplikasi}

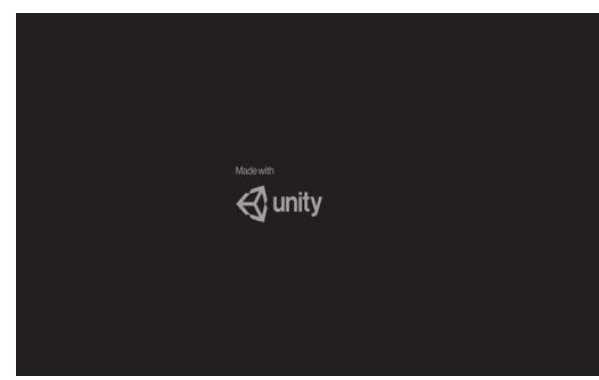

Gambar 6. Halaman Awal AR-CA

Ketika logo aplikasi di tekan maka akan muncul halaman awal aplikasi berupa flash video gambar relief Candi beserta ikon hewan yang menjadi tokoh cerita relief.

\section{Halaman Loading}

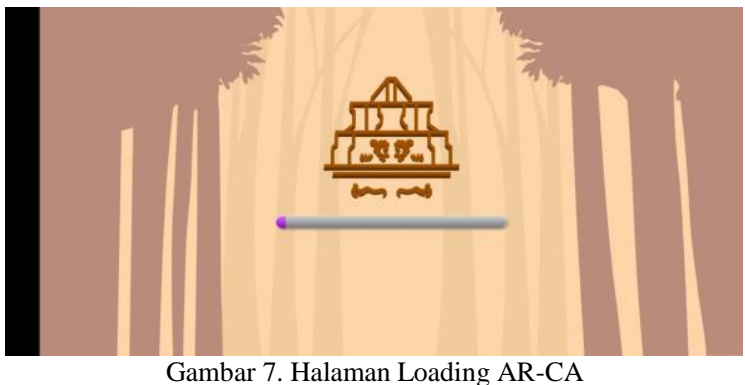

Setelah halaman awal aplikasi muncul halaman loading dan nantinya akan ada logo besar dari aplikasi AR-CA berupaikon harimau dan banteng.

\section{Halaman Menu Utama}

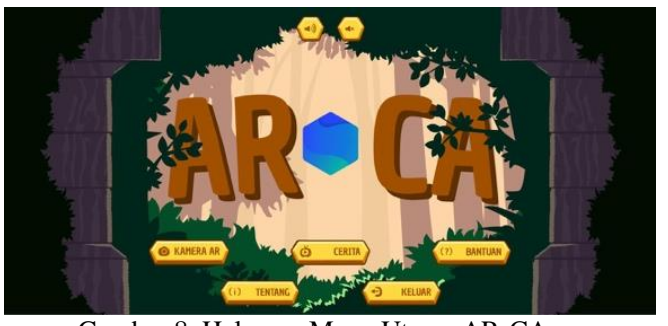

Gambar 8. Halaman Menu Utama AR-CA

Pada halaman menu utama terdapat background berupa latar belakang Siluet Candi Jago yang dikelilingi hutan dan terdapat beberapa hewan sebagai tokoh utama cerita antara lain serigala, harimau, banteng, angsa, dan kura-kura untuk mendeskripsikan icon Candi Jago. Pada menu utama akan ada pilihan control panel yang akan menjadi pilihan pengguna. Berikut macam-macam control panel yang terdapat pada menu utama.

$$
\text { a. AR Camera }
$$

AR Camera digunakan sebagai pengumpul informasi kolaborasi pengguna dan mengirimkannya untuk diproses.

$$
\text { b. Cerita }
$$

Story berisikan tiga cerita fabel yang terdapat pada teras pertama Candi Jago. Cerita tersebut terdiri dari Cerita Relief pertama berjudul Kera yang malang, cerita relief kedua berjudul Serigala si Penghasut, cerita ketiga berjudul Kura-kura yang bandel.

\section{c. Bantuan}

Bantuan berupa pertanyaan dan jawaban yang dapat membantu pengguna guna menjalankan aplikasi dengan lancar.

d. Tentang Aplikasi

Pada panel ini berisi keterangan mengenai aplikasi serta identitas dari tim penyusun aplikasi.

$$
\text { e. Keluar }
$$

Keluar merupakan keterangan untuk dapat keluar dari aplikasi. Pada control panel ornamen yang digunakan berupa daun, bunga, serta beberapa ornamen lain yang diambil dari benda-benda di hutan agar terlihat menyatu dengan tema.

\section{Halaman Menu AR Camera}

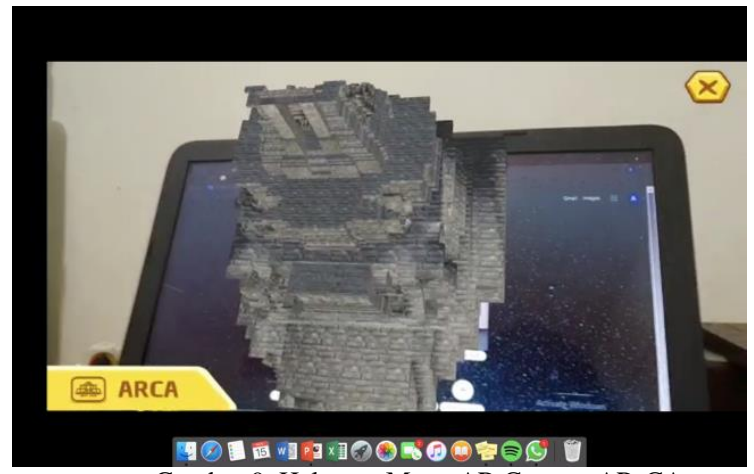

Gambar 9. Halaman Menu AR Camera AR-CA

Pada menu AR Camera, pengguna bisa menggunakan dengan memindai objek maker yang dalam hal ini adalah relief yang terdapat pada Candi Jago. Ketika relief cerita pertama dipindai dengan AR Camera maka akan muncul cerita video animasi cerita yang terdapat dalam relief tersebut. Pada pojok kanan atas terdapat tombol back untuk kembali ke menu utama dan pada pojok kanan bawah terdapat tombol panah arah yang berguna untuk mengarahkan pindaian video yang muncul pada marker.

\section{Halaman Menu Story}

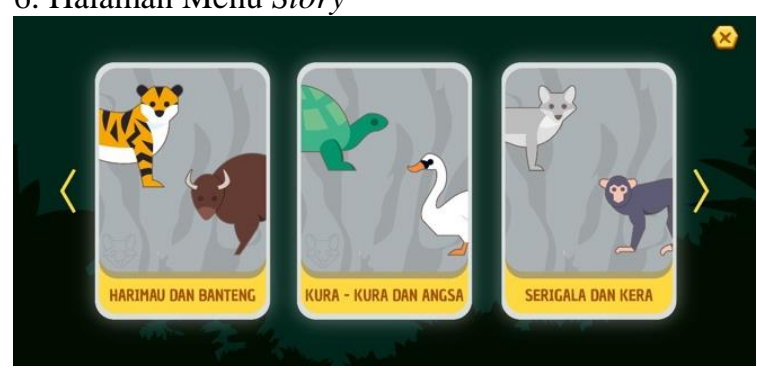

Gambar 10. Halaman Menu Story AR-CA 
Halaman menu story merupakan kumpulan video animasi yang terdapat pada relief-relief di Candi Jago. Pada halaman menu story nantinya terdapat background bertema Candi Jago dan hewan-hewan animasi. Halaman menu story dapat digunakan pengguna saat pengguna tidak berkunjung ke lokasi Candi Jago untuk dapat langsung mengerti mengenai Cerita Relief yang ada Pada teras awal Candi Jago.

\section{Halaman Puzzle Candi Jago}

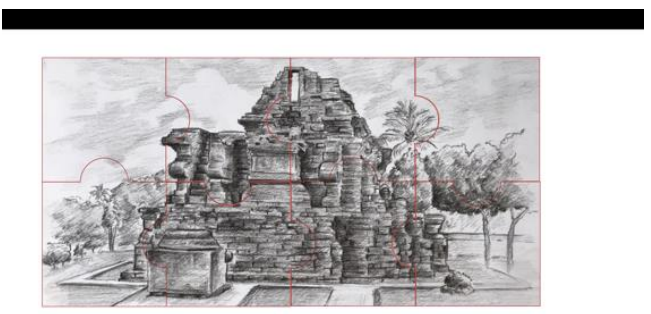

Gambar 11. Halaman Puzzle Candi Jago

Halaman Puzzle Candi Jago bertujuan untuk mengenalkan bentuk Candi Jago secara utuh kepada pengguna. Jika pengguna sudah menyelesaikan puzzle gambar Candi Jago, pengguna dapat memindai gambar tersebut dengan AR Camera, maka akan muncul Objek Candi Jago 3D serta memperlihatkan bagian teras yang menjadi cerita pada aplikasi AR-CA.

8. Tampilan Potongan Video Animasi Cerita Harimau dan Banteng

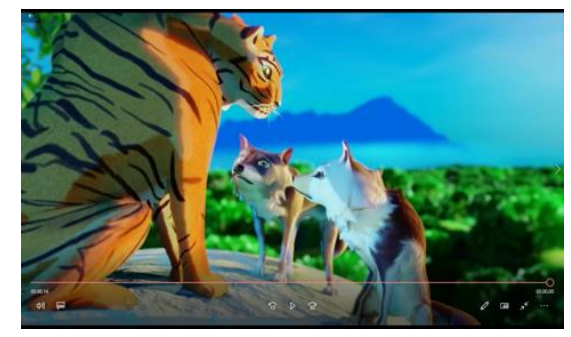

Gambar 12. Potongan Video Harimau dan Banteng

Video animasi cerita akan muncul ketika menggunakan AR Camera dan memindai relief yang terdapat pada Candi Jago sesuai cerita. Video animasi juga akan muncul pada menu story, ketika pengguna tidak dapat berkunjung lengsung ke Candi Jago.

\section{KESIMPULAN}

Berdasarkan hasil wawancara, semua responden memilih video animasi sebagai wujud pengenalan cerita yang terdapat dalam relief Candi Jago. Pemilihan video animasi menjadi lebih mudah dikarenakan dapat dinikmati dan mudah dipahami oleh berbagai kalangan. Hal tersebut sejalan dengan pendapat Wuryanta (2017) Teknologi multimedia tidak hanya mengubah cara berkomunikasi tradisional yang bersifat manual tapi juga bersifat digital, inovatif, cepat dan interaktif. Pengemasan Video animasi pada aplikasi AR-CA dibantu dengan menggunakan AR (Augmented Reality). Terdapat enam tahapan dalam penyusunan konsep cerita digital relief Candi Jago dengan menggunakan AR. Pertama, pemilihan cerita yang terdapat dalam relief Candi Jago. Kedua, mengubah ketiga cerita yang telah dipilih, berupa teks cerita menjadi teks drama. Ketiga, menentukan marker agar dapat menampilkan objek virtual. Keempat, menentukan tokoh-tokoh sentral dalam setiap cerita yang telah dipilih sebagai icon cerita. Kelima, membuat video animasi berdasarkan teks drama yang telah dibuat pada tahap kedua. Keenam, merancang aplikasi AR sebagai jembatan marker yang akan menampilkan objek virtual.

AR-CA dipilih sebagai nama aplikasi ini dengan beberapa konsep yang akan ditampilkan antara lain. Pertama, logo aplikasi AR-CA pada android. Kedua, halaman awal aplikasi. Ketiga, halaman Loading aplikasi AR-CA. Keempat, halaman menu utama. Kelima, halaman menu AR kamera. Keenam, halaman menu story. Ketujuh, halaman puzzle Candi Jago. Kedelapan, Potongan video animasi cerita berdasarkan halaman menu story yang dipilih. Cerita Pertama berjudul Kera yang malang, cerita kedua berjudul Serigala si Penghasut, cerita ketiga berjudul Kura-kura yang bandel.

\section{DAFTAR PUSTAKA}

ARIFTAMA, B., et al., 2018. Mobile Augmented Reality Pengenalan Situs Sejarah Kawasan Banten Lama dengan Metode Marker Based Tracking: Jurnal Teknologi Rekayasa, 3 (2), pp.255-260

APRIYANI, M.E., \& ROBIE GUSTIANTO., 2015. Augmented Reality sebagai Alat Pengenalan Hewan dengan Animasi 3D menggunakan Metode Single Marker: Jurnal Infotel, 7 (1), pp. 47-52

ASANIYAH, NENENG., 2017. Pelestarian Informasi Kolega Langka: Digitalisasi, Restorasi, Fumigasi: Buletin Perpustakaan Universitas Islam Indonesia, Nomor 57

BAYTAK, A., TARMAN, B., \& AYAS, C., 2018. Experiencing Technology Integration In Education: Children's Perceptions. International Electronic Journal of Elementary Education, 3 (2), pp.139-151

BRATA, K.C., ADAM, H.B., dan YUDHA A.P., 2017. Pengembangan Aplikasi Mobile Augmented Reality untuk Mendukung Pengenalan Koleksi Museum: Jurnal Teknologi Informasi dan Ilmu Komputer (JTTIK), 5 (3), pp.347-352

BRATA, K.C AND LIANG, D., 2019. An effective approach to develop location-based augmented reality information support. 
International Journal of Electrical and Computer Engineering, 9(4), p.3060.

COURDUFF, J., 2011. One Size Never Fits all: Tech Integration for Special Needs. Learning\&Leading with Technology, 38 (8), pp. 16-19.

FIAJI, N.A., 2019. Pergeseran Nilai Moral dalam Meme "Kids Jaman Now": Waskita, 2 (1), pp.91-102

JUNIAWAN, F.P., 2019. Pengenalan Alat Musik Tradisional Bangka dengan Marker-Based Augmented Reality: Register: Jurnal Ilmiah Teknologi Sistem Informasi, 5 (2) 78-92

MATSUN, RAMADHANI, D. \& LESTARI, I., 2018. Pengembangan Bahan Ajar Listrik Magnet Berbasis Androdid Di Program Studi Pendidikan Fisika Ikip Pgri Pontianak. Jurnal Pendidikan Matematika dan IPA. IX(1), pp.99-107.

PRASETIYO, T.K., 2017. Pengembangan Media Augmented Reality untuk Program Keahlian Teknik Gambar Bangunan di Sekolah Menengah Kejuruan: JINOTEP, 2 (1), pp.37-46

WURYANTA, A.G.E.W., 2017. Digitalisasi Masyarakat: Menilik Kekuatan dan Kelemahan Dinamika Era Informasi Digital dan Masyarakat Informasi: Jurnal Ilmu Komunikasi, 1(2), pp.131-142 
Halaman ini sengaja dikosongkan 